\title{
Rancang Bangun Perpustakaan Digital Berbasis Document Management System pada Fakultas Ilmu Komputer UNSIKA
}

\author{
Yayan Gustiana $^{1 *}$, Jajam Haerul Jaman ${ }^{2}$, Nono Heryana ${ }^{3}$ \\ ${ }^{1,2,3}$ Teknik Informatika, Fakultas Ilmu Komputer, Universitas Singaperbangsa Karwang, Karawang \\ 1,2,3 Jl. HS. Ronggo Waluyo, Puseurjaya, Telukjambe Timur, 41361, Karawang, Indonesia \\ email: 'yayan.gustiana@gmail.com, ${ }^{2}$ jajam.haeruljaman@staff.unsika.ac.id, ${ }^{3}$ nono.heryana@staff.unsika.ac.id
}

Received: 16 Maret 2018; Revised:11 Mei 2018; Accepted: 13 Mei 2018

Copyright @2018 Politeknik Harapan Bersama Tegal. All rights reserved

\begin{abstract}
A book is a reading tool for everyone, it is very important for an institution to keep knowledge going and generate new knowledge. In the library of the Faculty of Computer Science Unsika, one of the obstacles that is the library space where the books are less adequate and difficult to find the title of research for final students because the title should not be the same. Development of a library with Document Management System based is a method in solving the problem, it is expected to provide solutions in achieving a document management. Can accommodate all books uploaded by users, given permissions and speed in the deployment to all users. Development of this modeling tool using the method. Which is in accordance with the wishes of customers. Database storage using MySQL, Object Oriented Programming (OOP) programming language using the Code Igniter (CI) framework. Based on the results of simple random sampling of 35 respondents $86.80 \%$ say agree to the digital library. the concept of document management system required large storage media, server and good local connectivity. This function can also be a stepping stone to do research.
\end{abstract}

Abstrak - Buku merupakan sarana baca bagi setiap orang, sangat penting bagi suatu instansi agar pengetahuan terus berputar dan menghasilkan pengetahuan-pengetahuan baru. Pada perpustakaan Fakultas Ilmu Komputer Unsika salah satu kendala yang dihadapi adalah ruang perpustakaan tempat buku-buku yang kurang memadai dan kesulitan pencarian judul penelitian untuk mahasiswa tingkat akhir karena judul tidak boleh sama. Pengembangan perpustakaan dengan berbasis Document Management System merupakan suatu metode dalam pemecahan masalah tersebut, ini diharapkan dapat memberikan solusi dalam tercapainya suatu pengelolaan dokumen. Dapat menampung semua buku yang di upload oleh user, diberikan permissions serta mempermudah dalam penyebaran ke seluruh pengguna. Pengembangan perpustakaan ini menggunakan metode Software Development Life Cycle (SDLC) dengan model prototype karena ruang lingkupnya sedang, dan sistem yang dikembangkan merupakan sistem yang sesuai dengan keinginan pelanggan. Penyimpanan basis data menggunakan MySQL, Bahasa pemrograman Object Oriented Programing (OOP) dengan menggunakan framework Code Igniter (CI). Berdasarkan hasil simple random sampling dari 35 responden $86,80 \%$ mengatakan setuju untuk perpustakaan digital. konsep document management system diperlukan media penyimpanan

*) Corresponding author: Yayan Gustiana

Email: yayan.gustiana@gmail.com besar, server dan konektivitas lokal yang baik. Fungsi rekomendasi penelitian ini juga bisa jadi batu loncatan untuk mahasiswa tingkat akhir dalam mengerjakan penelitian lebih awal.

Kata Kunci - rancang bangun, perpustakaan digital, document management system.

\section{PENDAHULUAN}

Perpustakaan merupakan kumpulan pengetahuan yang tersusun dan tersimpan pada suatu tempat. Perpustakaan menjadi gudang ilmu bagi banyak orang dan sarana berbagi ilmu pengetahuan. Pada hakikatnya adalah tempat menyimpan buku-buku dan dokumen [1]. Adapun permasalahan yang ditemukan dalam perpustakaan yaitu berkurangnya buku seperti hilang, dicuri atau rusak. Masih kurangnya timbal balik pengetahuan setelah membaca, seperti pendokumentasian atau reproduksi pengetahuan baru [2]. Diperlukan tempat yang besar untuk penyimpanan buku dan ruang yang luas untuk pengunjung perpustakaan. Dengan berkembangnya teknologi dan informasi yang pesat. Di dalam perpustakaan diperlukan pengelolaan, agar ilmu pengetahuan tersebut dapat tersimpan dengan baik, tidak tercuri, berkurang, rusak ataupun hilang. Oleh sebab itu di dalam sebuah perpustakaan dibutuhkan penerapan konsep Document Management System.

Sistem manajemen dokumen atau Document Management System (DMS) adalah pengelolaan dokumen secara elektronik yang diterapkan pada suatu organisasi [3]. Dengan penerapan DMS pada perpustakaan, maka akan diberlakukan digitalisasi dari buku-buku menjadi dokumen elektronik yang dapat mengurangi risiko buku rusak atau hilang. Jika hilang dapat dilakukan retrieval atau pengambilan dokumen dari storage. Untuk mempermudah publish dokumen dan sekaligus menamabah ruang baca, pengunjung perpustakaan dapat mengaksesnya menggunakan media elektronik seperti smartphone dan notebook. Sebagai timbal balik ilmu pengetahuan, pengunjung dapat melakukan upload dokumen penelitiannya. Setiap dokumen yang masuk akan meminta konfirmasi kepada admin, ini agar dokumen yang di publish sesuai dengan kebutuhan perpustakaan [2]. Beberapa kelebihan DMS yaitu dokumen akan mudah dikelola, mudah 
dicari, dapat dicetak kembali. Manfaat lainnya dapat mendukung proses bisnis suatu instansi yang membutuhkan pelayanan dokumen secara cepat.

Penelitian menggunakan pendekatan kuantitatif, karena penelitian ini menggunakan populasi dan sampel [4]. Tujuan utama perpustakaan digital berbasis document management system di fakultas ilmu komputer, agar mahasiswa tingkat akhir tidak kesulitan dalam pencarian judul skripsi dan referensi buku sebagai bahan pengetahuan. Tidak terjadi duplikasi penelitian dengan angkatan sebelumnya, serta menumbuhkan minat baca mahasiswa dan interaksi mereka terhadap ilmu pengetahuan.

\section{PENELITIAN YANG TERKAIT}

Pengembangan DMS di PT. Geotama Energi telah mampu melakukan pengelolaan data-data cekungan, blok, lapangan serta sumur minyak dan gas. Dengan adanya sistem ini diharapkan perusahaan pengelolaan SDA terutama minyak dan gas dapat menyimpan data-data histori dari kegiatan eksplorasi dan eksploitasi secara rapi, terstruktur dan sistematis. Pada penelitian mendatang diharapkan sistem DMS mampu dikembangkan ke arah Knowledge Management System [5].

Dengan penerapan risiko teknologi informasi manajemen pada sistem manajemen dokumen dalam risiko JATEL dapat dikelola dan dicegah dengan menghilangkan sumber-sumber risiko atau mengurangi kemungkinan terjadinya secara substansial [6]. Penelitian lain menunjukkan bahwa kemudahan penggunaan adalah faktor utama dalam keputusan bagi mereka yang telah memiliki sedikit pengalaman sebelumnya dengan EDMS, sementara sejumlah responden yang menerima EDMS mampu menggunakannya karena pelatihan dan dukungan dari organisasi mereka lebih baik dan melalui upaya pribadi mereka [7].

Penelitian melalui pengembangan website merupakan sebuah aplikasi intranet berbasis web yang menampung semua dokumen yang di upload, diberikan permissions serta mempermudah dalam penyebaran informasi ke seluruh user secara langsung [3]. Penelitian terkait dengan sebuah aplikasi dapat digunakan untuk baik di lingkungan internal perusahaan. Hasil dari pengujian menunjukkan bahwa aplikasi ini dapat memudahkan pencarian dokumen dengan sistem pengindeksan teks lengkap dan dokumen toko elektronik. Selain itu, aplikasi ini mampu mengirimkan dokumen secara elektronik karena itu kurir dan fax mesin tidak diperlukan lagi [8].

Melihat dari kelima penelitian sebelumnya, maka penulis akan melakukan penelitian tentang aplikasi perpustakaan berbasis document management system. Perbandingan dengan penelitian sebelumnya yaitu, studi kasus dilakukan di fakultas ilmu komputer unsika, hasil perancangan aplikasi ini yaitu perpustakaan digital berbasis web. Dengan adanya manajemen asset dokumen berupa jurnal, skripsi atau karya ilmiah ilmu komputer yang dapat dikelola, disimpan, di unduh dan bisa menghasilkan timbal balik berupa pengetahuan baru, terjalinnya interaksi knowledge share antara mahasiswa dan dosen.

\section{METODE PENELITIAN}

Metodologi pengembangan sistem yang digunakan dalam penelitian ini yaitu SDLC (System Development Life Cycle) dengan model yang dipilih yaitu prototype. Tahapan-tahanpan yang ada di model prototype ini yaitu analisa kebutuhan, membangun prototype, evaluasi prototype, pengkodean sistem, pengujian sistem, evaluasi sistem, dan deployment (DMS), diperlihatkan pada Gbr.1 [9] .

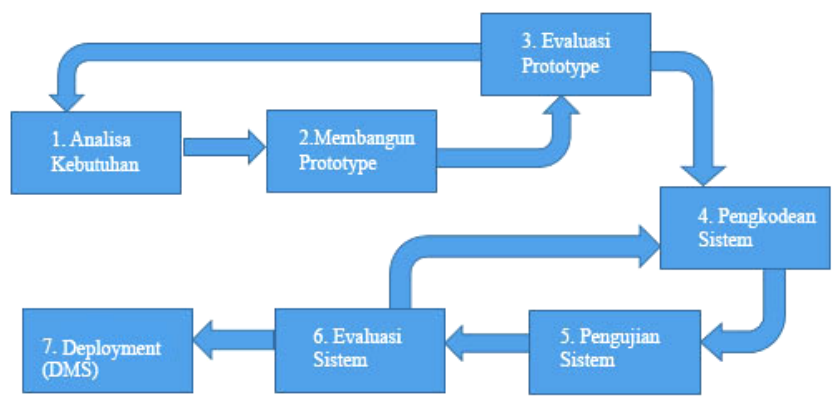

Gbr. 1 Alur penelitian[10]

Identifikasi kebutuhan dilakukan untuk mendeskripsikan kebutuhan sistem yang akan dibuat berdasarkan keinginan user. Dari hasil kuesinoer dan observasi penullis mendapatkan data terkait dengan analisis sistem yang berjalan, identifikasi masalah, usulan penyelesaian masalah dan identifikasi kebutuhan sistem pada perpustakaan Fakultas Ilmu Komputer UNSIKA. Pembangunan prototype dilakukan dari hasil analisa kebutuhan, dengan cara mendesain Unified Model Language (UML) dan Interface aplikasi. Evaluasi prototype dilakukan dengan Pengurus Repository Fasilkom Unsika untuk mendapatkan kesepakatan dalam perancangan.

Pada tahap pengkodean sistem, desain prototype yang diterjemahkan ke dalam baris program dengan menggunakan framework Codeigniter dan basis data MySQL. Setelah pengkodean sistem selesai, langkah selanjutnya adalah melakukan pengujian sistem terhadap aplikasi yang telah dibuat. Dalam penelitian ini penulis melakukan dua jenis pengujian yaitu Black box dan White Box Testing, Karena metode pengujian tersebut dapat mengetahui apakah aplikasi sudah sesuai dengan fungsi dan alur path atau belum. Untuk memastikan rancang bangun perpustakaan digital berbasis document management system ini dapat diterima user, maka pada evaluasi sistem dilakukan teknik angket atau kuesioner dengan responden mahasiswa.

Pada tahap deployment ini peneliti membaginya menjadi dua yaitu, arsitektural desain dan pemasangan aplikasi. Dalam arsitektural desain terdapat beberapa poin, pertama, struktur fungsional diamana fungsi-fungsi aplikasi tersebut dikelompokkan berdasarkan actor. Kedua, struktur implementasi merupakan keterkaitan hubungan antara hardware, software dan brainware. Ketiga, struktur fisik merupakan struktur media yang saling terhubung untuk menjalankan aplikasi[10].

Siklus Document Management System yang akan diterapkan pada aplikasi yaitu[3].

1) Metadata: Metadata yaitu identitas suatu dokumen, dimana dalam buku-buku perpustakaan diperlukan untuk mempermudah pencarian. Contoh metadata buku adalah tanggal, judul, penulis, penerbit, tahun terbit dan lain-lain. 
2) Capture: Dimana dokumen masih yang masih berbentuk buku, maka diperlukan proses konversi dari gambar kedalam teks digital.

3) Indexing: Index dokumen ini digunakan untuk melacak, pengklasifikasian yang dilakukan melalui metadata atau kata yang diekstrak dari isi dokumen. Fungsi utama dari indexing sendiri untuk mendukung pengambilan dokumen(retrieval). Pembuatan index topology diperlukan untuk melakukan pengambilan cepat (rapid retrieval).

4) Storage: Menyimpan dokumen elektronik. Dimana mencakup pengelolaan dokumen seperti: Di mana mereka disimpan, disusun berdasarkan kategori, dan perpindahan dokumen dari satu media penyimpanan ke media penyimpanan lainnya.

5) Retrieval: Pengambilan dokumen dari storage, dimana saat dokumen itu dibutuhkan. Pengambilan suatu dokumen dilakukan dengan menetukan indeks yang unik atau indeks dasar melalui pencarian pengguna, jika indeks cocok dengan metadata dari dokumen yang dituju maka dokumen tersebut dapat diambil.

6) Distribusi: Distribusi dokumen harus memiliki format yang tidak dengan mudah diubah. Dokumen yang di distribusi harus melewati validasi terlebih dahulu.

7) Security: Kemanan dokumen dipegang penuh oleh admin, dimana keamanan tersebut meliputi, pengunggahan, validasi, distribusi, dan pencetakan dokumen. Penciptaan PDF merupakan elemen penting untuk mencegah perubahan atau penggunaan yang tidak diinginkan.

8) Workflow: Merupakan alur kerja dari document management system yang diterapkan pada suatu instansi, mencakup alur pengunggahan, validasi, pengambilan, pencetakan, dan distribusi dokumen.

9) Kolaborasi: Kolaborasi dalam document management system. Dalam bentuk dasarnya, colabortive DMS harus memungkinkan dokumen diakses dan diambil oleh pengguna yang diizinkan (authorized user).

10) Versioning: Merupakan log akses dari buku yang diambil dan dilakukan pengguna, agar tetap terus terjaga keamanannya.

11) Searching: Mencari dokumen dan berkas menggunakan atribut atau pencarian teks lengkap (full text search). Dokumen dapat dicari menggunakan berbagai atribut dan isi dokumen.

12) Integrasi: Mengintegrasikan document management system dengan aplikasi lainnya dengan tujuan memperbaiki proses bisnis yang ada.

13) Validasi: Validasi ini meliputi approving, pengecekan metadata, dan tipe dokumen yang dilakukan oleh admin.

14) Publishing: Publishing disini melibatkan public viewing hanya dapat diakses oleh fakultas ilmu komputer, authorize dalam pengambilan dokumen, printing dan approving dokumen yang diunggah oleh pengguna.

\section{HASIL DAN PEMBAHASAN}

\section{A. Analisa Kebutuhan}

Identifikasi kebutuhan dilakukan untuk mendeskripsikan kebutuhan sistem yang akan dibuat berdasarkan keinginan user[11]. Berdasarkan hasil Kuesioner dan observasi terdapat beberapa pendefinisian masalah sebagai berikut:
- Penginputan judul buku atau skripsi masih ada yang dicatat pada sebuah buku khusus.

- Ada beberapa judul buku atau skripsi yang tidak tercatat.

- Mahasiswa fakultas ilmu komputer yang menempuh tingkat akhir kesulitan dalam menentukan judul penelitian, Karena judul yang diajukan harus berbeda dengan penelitian mahasiswa terdahulu.

- Tempat penyimpanan buku dan ruang baca yang terbatas.

Usulan penyelesaian masalah sebagai berikut:

- Penginputan judul buku atau skripsi dapat melalui aplikasi perpustakaan digital oleh mahasiswa atau dosen Fakultas Ilmu Komputer UNSIKA, dan pengelola hanya mengkonfirmasi buku yang masuk pada perpustakaan.

- Buku yang di masukan oleh mahasiswa melalui aplikasi akan tercatat langsung di database.

- Mahasiswa Fakultas Ilmu Komputer UNSIKA yang menempuh tingkat akhir tidak akan khawatir judul penelitiannya akan sama, karena dapat melihat judul penelitian terdahulu dengan mudah dengan fitur pencarian buku yang ada di aplikasi.

- Penyimpanan buku akan dikelola secara digital melalui sistem, dan ruang baca bertambah karena aplikasi dapat diakses menggunakan jaringan wireless lokal UNSIKA.

Kebutuhan Fungsional merupakan kebutuhan prosesproses aplikasi yang dapat dilakukan oleh pengguna sebagai berikut:

- Pengguna dapat memasukan data buku (judul, kategori, ISBN, penulis, penerbit, keterangan, dan dokumen pdf), mengubah data buku, verifikasi data buku, menghapus data buku, mencari data buku dan membuat laporan total buku.

- Pengguna dapat memasukan data kategori, mengubah kategori dan menghapus kategori.

- Pengguna dapat memasukan data user (nama, NPM, password, dan tanggal lahir), mengubah data user, mengubah data user, menghapus data user, mencari user.

- Pengguna dapat memasukan data penelitian, mengubah data penelitian, menghapus data penelitian, mencari data penelitian, dan verifikasi penelitian.

- Pengguna dapat melihat log aktivitas, membuat laporan log dan mencari log aktivitas.

Kebutuhan Non Fungsional pada penelitian ini terdiri dari kebutuhan preangkat keras dan perangkt lunak. Perangkat Keras/Hardware dengan spesifikasi Processor minimal $2.0 \mathrm{GHz}$, chace 4M, Harddisk minimal 500GB 7.2K RPM, Memory minimal 4GB, Monitor 15", Lain-lain seperti Mouse \& Keyboard. Untuk Perangkat Lunak (Software) yang dibutuhkan untuk mendukung aplikasi perpustakaan digital yaitu sistem operasi windows server, web server Xampp v3.2.2, TextEditor Notepad++ v7.5.1, Framework CodeIgniter v3.1.6, Browser menggunakan Mozilla firefox, Internet Explorer, dan Chrome.

Aplikasi perpustakaan digital digunakan oleh tiga jenis user. Untuk lebih jelasnya dapat dilihat pada TABEL I. 
TABEL I

JENIS USER

\begin{tabular}{|l|l|l|l|}
\hline User & $\begin{array}{l}\text { Tanggung } \\
\text { Jawab }\end{array}$ & Hak Akses & \multicolumn{1}{|c|}{ Pengalaman } \\
\hline $\begin{array}{l}\text { Pengurus } \\
\begin{array}{l}\text { Perpustakaan } \\
\text { (Admin) }\end{array}\end{array}$ & $\begin{array}{l}\text { mengelola } \\
\text { buku, } \\
\text { kategori, } \\
\text { dan } \\
\text { penelitian }\end{array}$ & $\begin{array}{l}\text { Menambah, } \\
\text { mengubah, } \\
\text { menghapus }\end{array}$ & $\begin{array}{l}\text { Min.mampu } \\
\text { mengoperasikan bisa } \\
\text { komputer dan bisa } \\
\text { menggunakan aplikasi } \\
\text { browser, CI, php, mysql, } \\
\text { dan Xampp }\end{array}$ \\
\hline Dosen & $\begin{array}{l}\text { Melihat, } \\
\text { Upload } \\
\text { buku dan } \\
\text { upload } \\
\text { penelitian }\end{array}$ & $\begin{array}{l}\text { Melihat, } \\
\text { mengambil }\end{array}$ & $\begin{array}{l}\text { Min.mampu } \\
\text { mengoperasikan } \\
\text { komputer dan bisa } \\
\text { menggunakan aplikasi } \\
\text { browser }\end{array}$ \\
\hline Mahasiswa & $\begin{array}{l}\text { Melihat, } \\
\text { dan Upload } \\
\text { buku }\end{array}$ & $\begin{array}{l}\text { Melihat, } \\
\text { mengambil }\end{array}$ & $\begin{array}{l}\text { Min.mampu } \\
\text { mengoperasikan } \\
\text { komputer dan bisa } \\
\text { menggunakan aplikasi } \\
\text { browser }\end{array}$ \\
\hline
\end{tabular}

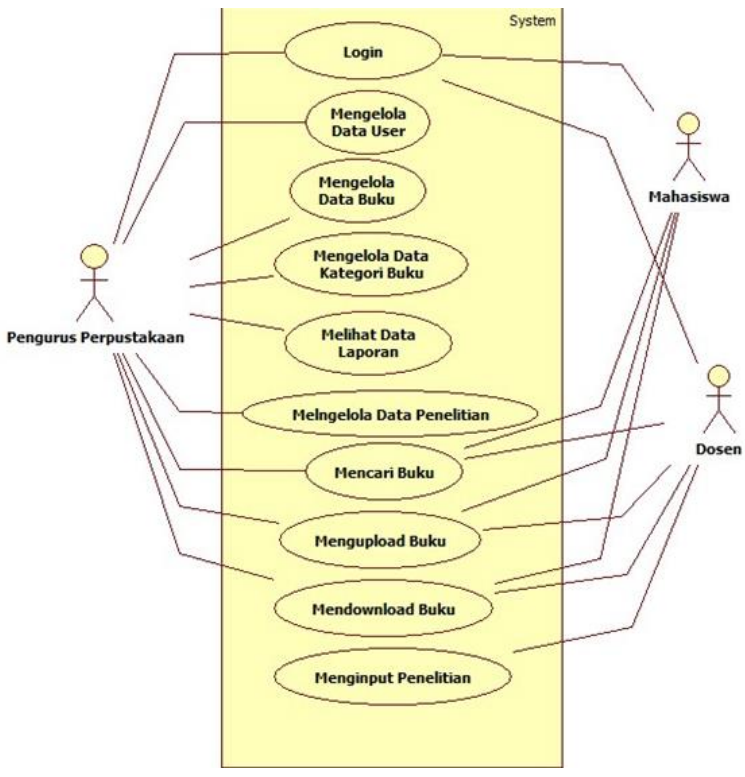

Gbr. 2 Use case aplikasi perpustakaan

TABEL II

TAMPILAN HALAMAN AWAL ADMIN

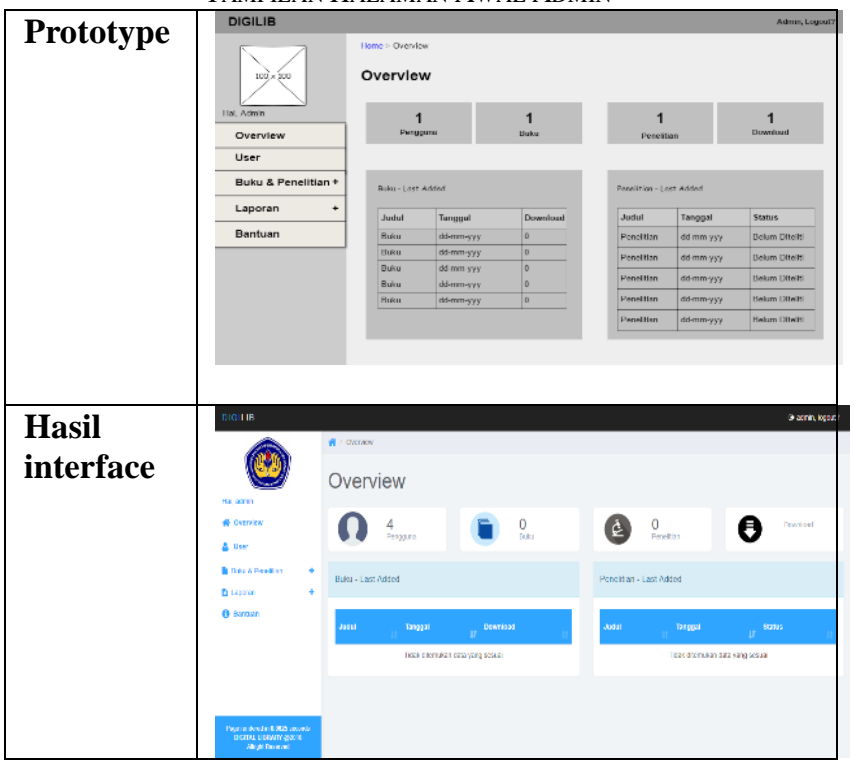

Dalam pengoperasian aplikasi perpustakaan document management system terdapat beberapa tipe user, maka dibedakan berdasarkan tanggung jawab, hak akses, dan pengalaman atau keahlian user [12]

\section{B. Use Case Aplikasi}

Dalam penelititan ini melibatkan 3 aktor yaitu pengurus perpustakaan, mahasiswa dan dosen seperti pada Gbr. 2. Dalam use case tersebut terdapat tiga aktor, yaitu pengurus perpustakaan, mahasiswa dan dosen. Untuk definisi setiap aktor yaitu: 1) Pengurus Perpustakaan, Pengguna yang bertugas mengelola data buku, data user, laporan perpustakaan dan juga dapat melakukan pencarian buku serta upload buku; 2) Dosen, Pengguna yang dapat melakukan pencarian buku, upload buku, download buku, dan input penelitian; 3) Mahasiswa, Pengguna yang dapat melakukan lihat rekomendasi penelitian, pencarian buku, upload buku, dan download buku.

\section{Representasi Interface}

Pada gambar merupakan hasil interface dari prototype yang telah di ubah ke dalam bahasa pemrograman. Pada Tabel II merupakan hasil representasi dari prototype halaman awal admin ke pengkodean sistem.

\section{Hasil Pengujian Aplikasi}

Testing dilakukan untuk menguji fungsionalitas dari aplikasi yang telah dibuat, apakah sudah sesuai dengan fungsinya masing-masing atau belum. Hasil pengujian tampak seperti pada Tabel III.

TABEL III

PENGUIIAN FUNGSI

\begin{tabular}{|c|c|c|c|}
\hline $\begin{array}{c}\text { Data } \\
\text { Masukan }\end{array}$ & $\begin{array}{l}\text { Hasil yang } \\
\text { diharapkan }\end{array}$ & Repon Sistem & $\begin{array}{c}\text { Hasil } \\
\text { Uji }\end{array}$ \\
\hline \multicolumn{4}{|c|}{ Hasil Uji Data Normal } \\
\hline \multicolumn{4}{|c|}{ Login } \\
\hline $\begin{array}{lr}\text { Masukkan } & \text { data } \\
\text { pada form login } \\
\text { yang benar } \\
\text { sesuai dengan } \\
\text { data di basis } \\
\text { data }\end{array}$ & $\begin{array}{l}\text { Masuk ke } \\
\text { halaman utama }\end{array}$ & $\begin{array}{l}\text { Menampilkan } \\
\text { halaman utama } \\
\text { sesuai dengan hak } \\
\text { akses }\end{array}$ & Diterima \\
\hline \multicolumn{4}{|c|}{ Mengelola Data User } \\
\hline $\begin{array}{l}\text { Memasukkan } \\
\text { data user pada } \\
\text { form tambah } \\
\text { data user sesuai } \\
\text { dengan aturan }\end{array}$ & $\begin{array}{l}\text { Berhasil } \\
\text { menyimpan ke } \\
\text { dalam basis data }\end{array}$ & $\begin{array}{l}\text { Berhasil } \\
\text { menyimpan ke } \\
\text { dalam basis data }\end{array}$ & Diterima \\
\hline $\begin{array}{lr}\text { Memilih dan } \\
\text { mengubah data } \\
\text { user pada form } \\
\text { user sesuai } \\
\text { dengan aturan }\end{array}$ & $\begin{array}{l}\text { Berhasil } \\
\text { mengubah data } \\
\text { dan menyimpan } \\
\text { ke dalam basis } \\
\text { data }\end{array}$ & $\begin{array}{l}\text { Berhasil } \\
\text { mengubah data } \\
\text { dan menyimpan ke } \\
\text { dalam basis data }\end{array}$ & Diterima \\
\hline $\begin{array}{l}\text { Memilih dan } \\
\text { menghapus data } \\
\text { user }\end{array}$ & $\begin{array}{l}\text { Berhasil } \\
\text { menghapus data } \\
\text { dari basis data }\end{array}$ & $\begin{array}{l}\text { Berhasil } \\
\text { menghapus data } \\
\text { dari basis data }\end{array}$ & Diterima \\
\hline \multicolumn{4}{|c|}{ Mengelola Data Buku } \\
\hline $\begin{array}{l}\text { Memasukkan } \\
\text { data buku pada } \\
\text { form tambah } \\
\text { buku sesuai } \\
\text { dengan aturan }\end{array}$ & $\begin{array}{l}\text { Berhasil } \\
\text { menyimpan ke } \\
\text { dalam basis data }\end{array}$ & $\begin{array}{l}\text { Berhasil } \\
\text { menyimpan ke } \\
\text { dalam basis data }\end{array}$ & Diterima \\
\hline $\begin{array}{l}\text { Memilih dan } \\
\text { mengubah data } \\
\text { buku pada form } \\
\text { buku sesuai }\end{array}$ & $\begin{array}{l}\text { Berhasil } \\
\text { mengubah data } \\
\text { dan menyimpan } \\
\text { ke dalam basis }\end{array}$ & $\begin{array}{l}\text { Berhasil } \\
\text { mengubah data } \\
\text { dan menyimpan ke } \\
\text { dalam basis data }\end{array}$ & Diterima \\
\hline
\end{tabular}




\begin{tabular}{|c|c|c|c|}
\hline dengan aturan & data & & \\
\hline $\begin{array}{l}\text { Memilih dan } \\
\text { menghapus data } \\
\text { buku }\end{array}$ & $\begin{array}{l}\text { Berhasil } \\
\text { menghapus data } \\
\text { dari basis data }\end{array}$ & $\begin{array}{l}\text { Berhasil } \\
\text { menghapus data } \\
\text { dari basis data }\end{array}$ & Diterima \\
\hline \multicolumn{4}{|c|}{ Mengelola Data Kategori } \\
\hline \begin{tabular}{lr}
\multicolumn{2}{l}{ Memasukkan } \\
data kategori \\
pada form \\
kategori sesuai \\
\multicolumn{2}{l}{ dengan aturan } \\
\end{tabular} & $\begin{array}{l}\text { Berhasil } \\
\text { menyimpan ke } \\
\text { dalam basis data }\end{array}$ & $\begin{array}{l}\text { Berhasil } \\
\text { menyimpan ke } \\
\text { dalam basis data }\end{array}$ & Diterima \\
\hline $\begin{array}{lr}\text { Memilih } & \text { dan } \\
\text { mengubah } & \text { data } \\
\text { kategori } & \text { pada } \\
\text { form } & \text { kategori } \\
\text { sesuai } & \text { dengan } \\
\text { aturan } & \end{array}$ & $\begin{array}{l}\text { Berhasil } \\
\text { mengubah dan } \\
\text { menyimpan ke } \\
\text { dalam basis data }\end{array}$ & $\begin{array}{l}\text { Berhasil } \\
\text { mengubah dan } \\
\text { menyimpan ke } \\
\text { dalam basis data }\end{array}$ & Diterima \\
\hline \multicolumn{4}{|c|}{ Mengelola Data Penelitian } \\
\hline $\begin{array}{l}\text { Memasukkan } \\
\text { data penelitian } \\
\text { padar form } \\
\text { penelitian sesuai } \\
\text { dengan aturan }\end{array}$ & $\begin{array}{l}\text { Berhasil } \\
\text { menyimpan ke } \\
\text { dalam basis data }\end{array}$ & $\begin{array}{l}\text { Berhasil } \\
\text { menyimpan ke } \\
\text { dalam basis data }\end{array}$ & Diterima \\
\hline $\begin{array}{l}\text { Memilih dan } \\
\text { mengubah data } \\
\text { penelitian pada } \\
\text { form penelitian } \\
\text { sesuai dengan } \\
\text { aturan }\end{array}$ & $\begin{array}{l}\text { Berhasil } \\
\text { mengubah data } \\
\text { dan menyimpan } \\
\text { ke dalam basis } \\
\text { data }\end{array}$ & $\begin{array}{l}\text { Berhasil } \\
\text { mengubah data } \\
\text { dan menyimpan ke } \\
\text { dalam basis data }\end{array}$ & Diterima \\
\hline $\begin{array}{l}\text { Memilih dan } \\
\text { menghapus data } \\
\text { penelitian }\end{array}$ & $\begin{array}{l}\text { Berhasil } \\
\text { menghapus data } \\
\text { dari basis data }\end{array}$ & $\begin{array}{l}\text { Berhasil } \\
\text { menghapus data } \\
\text { dari basis data }\end{array}$ & Diterima \\
\hline \multicolumn{4}{|c|}{ Mengelola Data Laporan } \\
\hline $\begin{array}{l}\text { Memilih periode } \\
\text { laporan buku }\end{array}$ & $\begin{array}{l}\text { Menampilkan } \\
\text { laporan sesuai } \\
\text { periode }\end{array}$ & $\begin{array}{l}\text { Menampilkan } \\
\text { laporan sesuai } \\
\text { periode }\end{array}$ & Diterima \\
\hline $\begin{array}{l}\text { Memilih periode } \\
\text { laporan log }\end{array}$ & $\begin{array}{l}\text { Menampilkan } \\
\text { laporan sesuai } \\
\text { periode }\end{array}$ & $\begin{array}{l}\text { Menampilkan } \\
\text { laporan sesuai } \\
\text { periode }\end{array}$ & Diterima \\
\hline \multicolumn{4}{|c|}{ Upload Buku (mahasiswa dan dosen) } \\
\hline $\begin{array}{l}\text { Memasukan } \\
\text { data buku pada } \\
\text { form upload } \\
\text { buku sesuai } \\
\text { dengan aturan }\end{array}$ & $\begin{array}{l}\text { Berhasil } \\
\text { menyimpan ke } \\
\text { dalam basis data }\end{array}$ & $\begin{array}{l}\text { Berhasil } \\
\text { menyimpan ke } \\
\text { dalam basis data }\end{array}$ & Diterima \\
\hline \multicolumn{4}{|c|}{ Download Buku } \\
\hline $\begin{array}{l}\text { Memilih } \\
\text { kategori, } \\
\text { memasukkan } \\
\text { judul buku, dan } \\
\text { memilih } \\
\text { download buku }\end{array}$ & $\begin{array}{l}\text { Berhasil } \\
\text { mengambil data } \\
\text { dari basis data }\end{array}$ & $\begin{array}{l}\text { Berhasil } \\
\text { mengambil data } \\
\text { dari basis data }\end{array}$ & Diterima \\
\hline \multicolumn{4}{|c|}{ Rekomendasi penelitian (mahasiswa) } \\
\hline $\begin{array}{l}\text { Memilih } \\
\text { kategori sesuai } \\
\text { dengan } \\
\text { penelitian yang } \\
\text { di inginkan } \\
\end{array}$ & $\begin{array}{l}\text { Menampilkan data } \\
\text { penelitian sesuai } \\
\text { kategori dari basis } \\
\text { data }\end{array}$ & $\begin{array}{l}\text { Menampilkan data } \\
\text { penelitian sesuai } \\
\text { kategori dari basis } \\
\text { data }\end{array}$ & Diterima \\
\hline Data Masukan & $\begin{array}{l}\text { Hasil yang } \\
\text { diharapkan }\end{array}$ & Repon Sistem & $\begin{array}{l}\text { Hasil } \\
\text { Uji }\end{array}$ \\
\hline \multicolumn{4}{|c|}{ Hasil Uji Data Tidak Normal } \\
\hline \multicolumn{4}{|c|}{ Login } \\
\hline 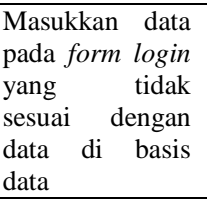 & $\begin{array}{l}\text { Menampilkan } \\
\text { pesan error } \\
\text { "Username atau } \\
\text { Password salah" }\end{array}$ & $\begin{array}{l}\text { Menampilkan } \\
\text { pesan error } \\
\text { "Username atau } \\
\text { Password salah" }\end{array}$ & Diterima \\
\hline \multicolumn{4}{|c|}{ Mengelola Data User } \\
\hline $\begin{array}{lr}\text { Salah } & \text { satu field } \\
\text { pada } & \text { form }\end{array}$ & $\begin{array}{l}\text { Menampilkan } \\
\text { pesan "kolom ini }\end{array}$ & $\begin{array}{l}\text { Menampilkan } \\
\text { pesan "kolom ini }\end{array}$ & Diterima \\
\hline
\end{tabular}

\begin{tabular}{|c|c|c|c|}
\hline $\begin{array}{l}\text { tambah data } \\
\text { user } \\
\text { dikosongkan } \\
\end{array}$ & diperlukan” & diperlukan” & \\
\hline \multicolumn{4}{|c|}{ Mengelola Data Buku } \\
\hline $\begin{array}{ll}\text { Salah satu field } \\
\text { pada } \quad \text { form } \\
\text { tambah buku } \\
\text { dikosongkan }\end{array}$ & $\begin{array}{l}\text { Menampilkan } \\
\text { pesan "kolom ini } \\
\text { diperlukan" }\end{array}$ & $\begin{array}{l}\text { Menampilkan } \\
\text { pesan "kolom ini } \\
\text { diperlukan" }\end{array}$ & Diterima \\
\hline \multicolumn{4}{|c|}{ Mengelola Data Penelitian } \\
\hline $\begin{array}{l}\text { Salah satu field } \\
\text { pada form } \\
\text { penelitian } \\
\text { dikosongkan }\end{array}$ & $\begin{array}{l}\text { Menampilkan } \\
\text { pesan "kolom ini } \\
\text { diperlukan" }\end{array}$ & $\begin{array}{l}\text { Menampilkan } \\
\text { pesan "kolom ini } \\
\text { diperlukan" }\end{array}$ & Diterima \\
\hline \multicolumn{4}{|c|}{ Upload Buku (mahasiswa dan dosen) } \\
\hline $\begin{array}{ll}\text { Salah } & \text { satu field } \\
\text { pada } & \text { form } \\
\text { upload buku } \\
\text { dikosongkan }\end{array}$ & $\begin{array}{l}\text { Menampilkan } \\
\text { pesan "kolom ini } \\
\text { diperlukan" }\end{array}$ & $\begin{array}{l}\text { Menampilkan } \\
\text { pesan "kolom ini } \\
\text { diperlukan" }\end{array}$ & Diterima \\
\hline
\end{tabular}

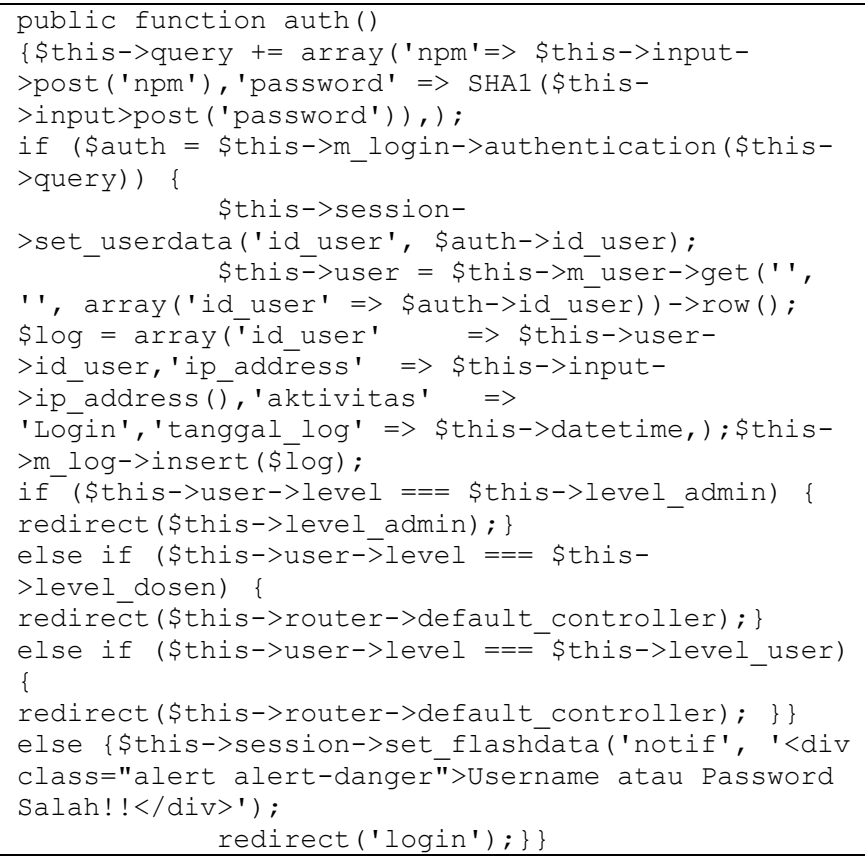

\section{Gbr. 3 Potongan coding application}

Pengujian fungsi dilakukan dengan pihak pengurus perpustakaan agar fungsi sudah dapat diterima dengan baik dan sesuai dengan yang di inginkan. Pada Gbr. 3 merupakan coding login dari aplikasi perpustakaan, dimana aplikasi akan mengambil kode npm dan password. lalu memeriksa apakah npm dan password tersebut valid atau tidak. Jika tidak ada aplikasi tersebut akan menampilkan password salah, dan apabila benar aplikasi tersebut akan merekam ip address user. Halaman yang ditampilkan ketika masuk diatur berdasarkan level dari user itu sendiri.

\section{E. Deployment (DMS}

Deployment diagram menunjukkan tata letak sebuah sistem secara fisik, menampakkan bagian- bagian software yang berjalan pada bagian-bagian hardware[ 13], seperti ada Gbr.4. 


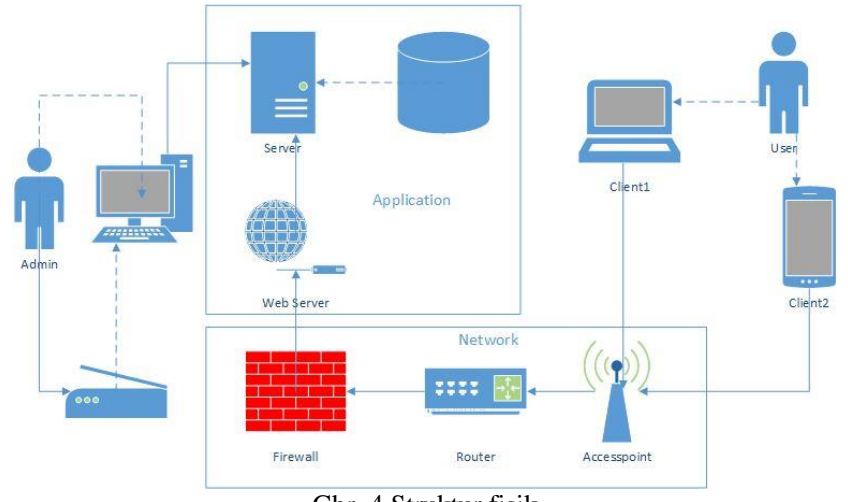

Gbr. 4 Struktur fisik

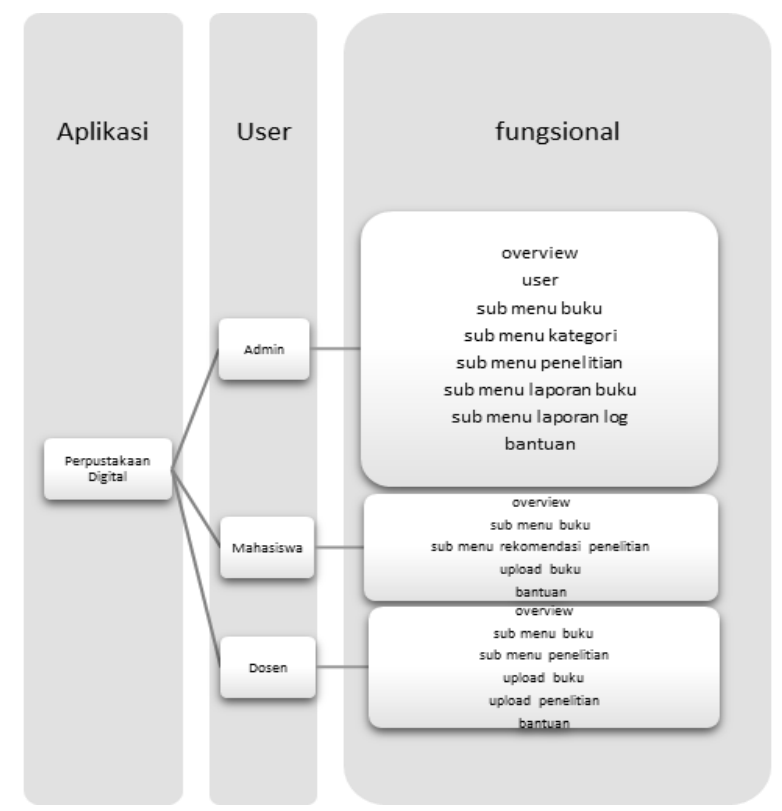

Gbr. 5 Struktur fungsional

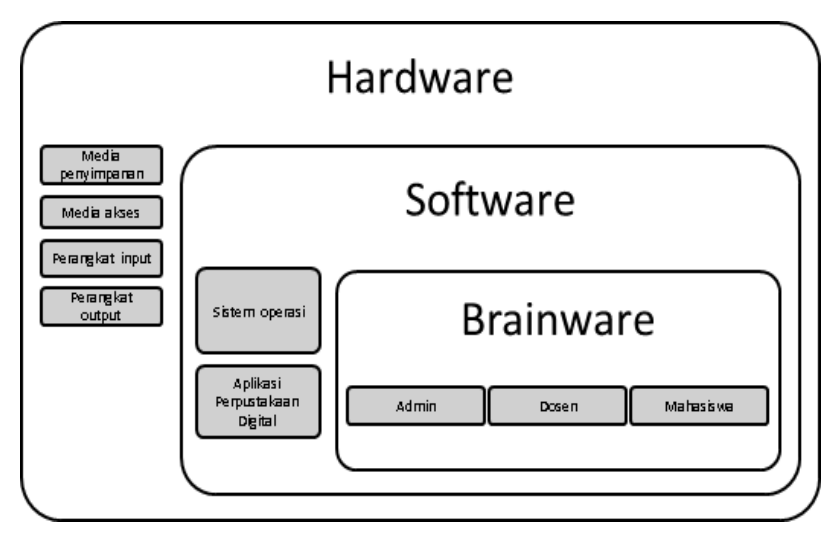

Gbr. 6 Struktur implementasi

Pada Gbr. 5 merupakan struktur fisik yang akan di implementasikan pada perpustakaan berbasis documenet management system [14]. Jaringan yang dipakai bersifat intranet, dengan ruang lingkup fakultas ilmu komputer unsika. Struktur fungsional Pada aplikasi perpustakaan digital dengan basis document management system terdapat 3 user, dimana masing-masing user terdapat beberapa fungsi yang sudah dapat dijalankan. a) Definisi fungsional user admin:

- Overview, menampilkan informasi last update penelitian dan buku.

- User, menampilkan daftar user dan opsi pengelolaan seperti tambah, edit, dan hapus user.

- Sub menu buku, terdapat pada menu buku dan penelitian. Berfungsi untuk menampilkan daftar buku dan opsi pengeloloaan seperti tambah buku, edit, hapus, dan validasi status buku.

- Sub menu kategori, terdapat pada menu buku dan penelitian. Berfungsi untuk menampilkan daftar kategori dan terdapat opsi seperti tambah, edit, dan hapus kategori.

- Sub menu laporan buku, terdapat pada menu laporan. Berfungsi untuk mengelola laporan buku.

- Sub menu laporan log, terdapat pada menu laporan. Berfungsi utntuk mengelola laporan $\log$.

- Bantuan, merupakan halaman panduan admin.

b) Defini fungsional user mahasiswa:

- Overview, menampilkan buku dan penelitian terbaru.

- Sub menu buku, terdapat pada menu buku dan penelitian. Berfungsi untuk menampilkan daftar buku.

- Sub menu rekomendasi penelitian, yang terdapat pada menu buku dan penelitian. Berfungsi untuk melihat daftar penelitian.

- Upload buku, Berfungsi untuk menyimpan data buku ke base data perpustakaan digital.

- Bantuan, berfungsi sebagai panduan pemakaian aplikasi.

c) Definisi fungsional user dosen:

- Overview, menampilkan buku dan penelitian terbaru.

- Sub menu buku, terdapat pada menu buku dan penelitian. Berfungsi untuk menampilkan daftar buku.

- Sub menu penelitian, yang terdapat pada menu buku dan penelitian. Berfungsi untuk melihat daftar penelitian.

- Upload buku, Berfungsi untuk menyimpan data buku ke base data perpustakaan digital.

- Upload penelitian, Berfungsi untuk menyimpan data penelitian ke base data perpustakaan digital

- Bantuan, berfungsi sebagai panduan pemakaian aplikasi.

d) Definisi hardware:

- Media penyimpanan, merupakan server yang dapat menampung data perpustakaan digital.

- Media akses, adalah media penghubung jaringan berupa wireless akses poin ataupun kabel local area network

- Perangkat input, bisa berupa scanner, komputer ataupun smartphone sebagai perangkat untuk memasukan data.

- Perangkat output, merupakan perangkat keluaran yang menampilkan hasil dari pengoperasian aplikasi seperti komputer dan smartphone.

e) Definisi software:

- Sistem operasi, merupakan perangkat lunak sistem yang mengatur sumber daya dari perangkat keras dan perangkat lunak.

- Aplikasi perpustakaan digital, adalah aplikasi yang akan di implementasi. 


\section{f) Definisi brainware:}

- Admin, merupakan pengelola perpustakaan yang nantinya akan mengatur proses berjalannya aplikasi perpustakaan digital.

- Mahasiswa, merupakan pengguna perpustakaan yang dilakukan pembatasan dalam hal upload buku harus melewati validasi admin dan tidak bisa upload penelitian.

- Dosen, merupakan pengguna perpustakaan yang dilakukan pembatasan dalam upload buku karena harus melewati validasi admin.

\section{F. Evaluasi Sistem}

Hasil evaluasi dilakukan dengan menggunakan angket atau kuesioner yang diberikan kepada 35 responden mahasiswa menggunakan teknik Simple Random Sampling [4]. Dimana diantaranya 7 orang angkatan 2013, 12 orang angkatan 2014, 2 orang angkatan 2015,8 orang angkatan 2016, dan 6 orang angkatan 2017. Penilaian tersebut disajikan dalam bentuk pilihan Antara 'Setuju' atau 'Kurang Setuju' dengan menggunakan User Acceptace Testing dengan perhitungan skala Guttman Cross-Sectional [15].

TABEL IV HASIL KUESIONER

\begin{tabular}{|c|c|c|}
\hline \multirow{2}{*}{ Pernyataan } & \multicolumn{2}{|c|}{ Kriteria Jawaban } \\
\cline { 2 - 3 } & KS & ST \\
\hline P1 & 5 & 30 \\
\hline P2 & 3 & 32 \\
\hline P3 & & 35 \\
\hline P4 & 4 & 31 \\
\hline P5 & 9 & 26 \\
\hline P6 & 10 & 25 \\
\hline P7 & 4 & 31 \\
\hline P8 & 2 & 33 \\
\hline Total & 37 & 243 \\
\hline Rata-rata & 5.29 & 30.38 \\
\hline
\end{tabular}

Berdasarkan tabel untuk Mengetahui posisi presentase jawaban setuju yang diperoleh dari kuesioner, maka dihitung terlebih dahulu kemudian ditempatkan dalam rentang presentase sebagai berikut:

- Jawaban "Setuju" rata-rata : 30,38/35 x $100 \%=86,8 \%$

- Jawaban "Kurang Setuju"rata-rata: 5,29/35 x 100\% $=15,11 \%$

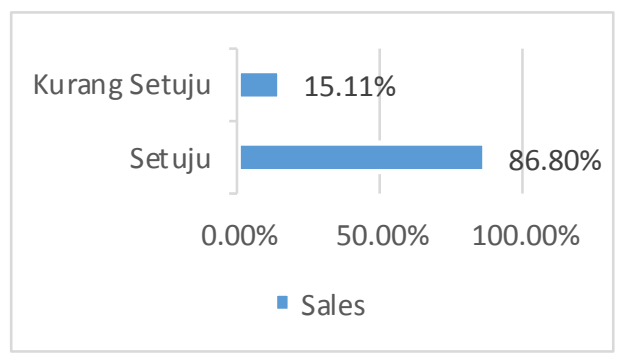

Gbr. 1 Grafik hasil

Merupakan gambaran grafik jawaban yang diperoleh dari responden.
TABEL V

NILAI INTERVAL

\begin{tabular}{|l|c|}
\hline \multicolumn{1}{|c|}{ Jawaban } & Nilai Interval \\
\hline Mendekati tidak setuju & $0 \%-50 \%$ \\
\hline Mendekati setuju dam tidak setuju & $50 \%$ \\
\hline Mendekati setuju & $50 \%-100 \%$ \\
\hline
\end{tabular}

Dari analisis skala Guttman, titik kesesuaian diatas 50\% yaitu $86,80 \%$, sehingga dapat dikatakan aplikasi perpustakaan digital berbasis document management system mendekati setuju

\section{KESIMPULAN}

Berdasarkan penelitian yang telah dilaksanakan maka aplikasi perpustakaan digital dibuat menggunakan pemrograman php dengan tools codeigniter dalam pengembangannya, dan mysql sebagai basis data. Aplikasi dapat digunakan untuk membaca buku, upload buku, dan melihat rekomendasi penelitian atau penelitian terdahulu. Berdasarkan hasil evaluasi user dengan menggunakan kuesioner, aplikasi perpustakaaan digital fasilkom memiliki persentase $86,80 \%$ dan termasuk dalam mendekati setuju pada interval $50 \%$ sampai $100 \%$. I

Dalam menerapkan konsep document management system pada aplikasi perputsakaan digital mulai dari rancangan prototype dan kebutuhan yang diperlukan seperti media penyimpanan dengan kapasitas besar, server yang mumpuni dan konektivitas lokal yang baik. Pengurus perpustakaan yang teliti dan cekatan dalam memilah dokumen juga sangatlah dibutuhkan, karena buku yang masuk setiap waktu akan menumpuk jika tidak terus diperbarui. Fungsi rekomendasi penelitian ini dapat membantu mahasiswa dalam melihat penelitian terdahulu maupun penelitian yang akan di pilih, bahkan bisa jadi batu loncatan untuk mengerjakan penelitian lebih awal. Sehingga dapat menghasilkan mahasiswa yang lulus tepat waktu.

Berdasarkan kesimpulan diatas dapat diajukan beberapa saran untuk penelitian selanjutnya. Untuk penelitian selanjutnya dapat dibuat menu sub upload khusus penelitian, karena upload masih bersifat umum. Penambahan fitur chat atau pesan ke user sebagai komunikasi user dan admin. Laporan pengelolaan penelitian agar dapat melihat daftar mahasiswa yang sudah mengambil judul penelitian yang ada pada perpustakaan digital. Dalam konsep document management system masih ada yang harus ditambahkan search berdasarkan kata pada text isi buku atau ekstrak searching. Karena perpustkaan digital ini hanya bersifat lokal, diharpakan untuk peneliti selanjutnya sudah dapat di hosting dan diperhatikan aspek keamanannya.

\section{UCAPAN TERIMA KASIH}

Ucapan terimakasih kepada rekan-rekan yang telah membanatu dan berpartisipasi dalam memberikan masukkan dan kritiknya mengenai penelitian mengenai aplikasi perpustakaan digital berbasis Document Management System. Terima kasih kepada Universitas Singaperbangsa Karawang dan Fakultas Ilmu Komputer Unsika yang telah memberikan tempat selama melakukan penelitian ini. 


\section{DAFTAR PUSTAKA}

[1] Republik Indonesia, "Undang-Undang Republik Indonesia Nomor 43 Tahun 2007 Tentang Perpustakaan,” p. 45, 2007.

[2] S. Jones, "EGovernment document management system: A case analysis of risk and reward," Int. J. Inf. Manage., vol. 32, no. 4, pp. 396-400, 2012

[3] Wahyuni, "PEMANFAATAN TEKNOLOGI SHAREPOINT DALAM PENGEMBANGAN WEBSITE DOCUMENT MANAGEMENT SYSTEM," Jakarta, 2011.

[4] Sugiyono, Statistika Untuk Penelitian. 2012

[5] D. I. Pt, G. Energi, S. P. Nugroho, O. S. Simanjuntak, and F. R. Kodong, "Pengembangan Document Management System Untuk Pengelolaan Sumur Minyak," TELEMATIKA, vol. 12, no. 01, pp. 63 67, 2015

[6] G. M. Husein and V. R. Imbar, "Analisis Manajemen Risiko Teknologi Informasi: Penerapan pada Document Management System di PT. Jabar Telematika (JATEL)," J. Tek. Inform. dan Sist. Inf., vol. 1, no. 2, pp. 2443-2229, 2015.

[7] F. Kaaki, C. Rayner, and M. Alshamrani, "Female users' acceptance of the electronic document management system (EDMS)," Proc. UKSim-AMSS 7th Eur. Model. Symp. Comput. Model. Simulation, EMS 2013, no. November, pp. 315-320, 2013.
[8] E. A. S, Jeff Edwin, "Rancang Bangun Aplikasi Document Management System Pada Bagian Persediaan Di Pt. Indonesia Indah Tobacco Citraniaga," Igarss 2014, vol. 3, no. 1, pp. 1-5, 2014.

[9] R. S. Pressman, Software Engineering A Practitioner's Approach 7th Ed-Roger S. Pressman. 2009.

[10] Wahyu Lukman Hakim, "Pengertian Prototype," Scribd.com, 2011 [Online].

Available: https://www.scribd.com/doc/58298607/Pengertian-Prototype.

[11] I. D. Rahayu, "Sistem Informasi Perpustakaan Berbasis Web Di Balai Pengkajian Dan Pengembangan Komunikasi Dan Informatika Surabaya," J. KOMUNIKASI, MEDIA DAN Inform., vol. 5, no. 3, pp. 143-152, 2016.

[12] I. Standard, "INTERNATIONAL STANDARD process baselining and analysis," vol. 2010, 2010.

[13] S. Nurajizah, "Sistem Informasi Perpustakaan Berbasis Web Dengan Metode Prototype: Studi Kasus Sekolah Islam Gema Nurani Bekasi," Pros. SNIT 2015, pp. 214-219, 2015.

[14] C. H. Kao and S. T. Liu, "Development of a Document Management System for Private Cloud Environment," Procedia - Soc. Behav. Sci., vol. 73, pp. 424-429, 2013.

[15] O. D. Iskani, "Skala Guttman Secara Tradisional ( Cross Sectional ) Revisi." 